\title{
LA ANTIGUA IGLESIA DE SAN PEDRO (ÍSCAR, VALLADOLID). EVIDENCIAS ARQUITECTÓNICAS ROMÁNICAS
}

\author{
Jorge Esteban Molina
}

\begin{abstract}
San Pedro es la gran desconocida de las iglesias de Íscar a consecuencia de la demolición de la mayor parte de sus estructuras arquitectónicas y de la insuficiente representatividad de las escasas evidencias conservadas, enmascaradas entre edificios contemporáneos. Sin embargo, el reciente derribo de uno de los inmuebles adosados en el extremo oriental del antiguo templo, donde se concentran los restos del periodo románico, ha sacado a la luz una parte determinante del ábside y el presbiterio así como el testero de cierre de la nave meridional, permitiendo su análisis en profundidad y una aproximación a lo que pudo ser la primitiva construcción.
\end{abstract}

Palabras clave: Siglo XIII; Románico; Arquitectura Mudéjar; Ábside; Presbiterio.

\section{THE FORMER CHURCH OF SAINT PETER (ÍSCAR, VALLADOLID): ROMANESQUE ARCHITECTURAL EVIDENCE}

Saint Peter is the great unknown of the Iscar churches due to the demolition of most of its architectural structures and the insufficient characteristics of the scarcely preserved evidence, hidden between contemporary buildings. Nevertheless, the recent demolition of one of the buildings attached to the eastern side of the former temple, where the Romanesque remains are concentrated, has brought to light a decisive part of the apse and the presbytery along with the front closure of the southern aisle. This discovery has allowed an indepth analysis and an approach to what could have been the primitive building.

Key words: 13th Century; Romanesque; Mudejar architecture; Apse; Presbytery.

La iglesia parroquial de San Pedro fue, junto con Santa María de los Mártires y San Miguel, uno de los tres templos de raíces románicas con los que llegó a contar en su momento la villa de Íscar, localidad situada al sureste de la actual provincia de Valladolid. De todos ellos es el único que lamentablemente no ha llegado a nuestros días como tal, debido a que su cierre al culto a mediados del siglo XIX y, sobre todo, un posterior cambio de funcionalidad, que llevó aparejada una serie de profundas transformaciones en su estructura a lo largo del siglo pasado, han conducido a que en la actualidad solamente se conserven algunas evidencias constructivas en los extremos de lo que fue el antiguo edificio, ya fueran éstas integrantes de la primitiva fábrica románica o pertenecientes a añadidos y reformas posteriores. 
A consecuencia de esas mutaciones San Pedro es, sin duda, la gran olvidada de las iglesias iscarienses y uno de los edificios más desconocidos del denominado románico mudéjar de la Tierra de Pinares ${ }^{1}$, estando prácticamente ausente en la bibliografía. No en vano, su elenco se circunscribe a una relación de los extractos más significativos de sus libros de fábrica entre los siglos XVI y $\mathrm{XVIII}^{2}$, y a una serie de jugosos apuntes históricos introducidos a finales de la pasada centuria ${ }^{3}$. En definitiva, un repertorio insuficiente a la hora de cumplir con el grado de conocimiento exigible para este edificio.

Con el objeto de arrojar más luz en este escenario, y con el aliciente que supone la reciente puesta al descubierto de una parte muy significativa de los restos románicos, surge la iniciativa de llevar a cabo un proyecto de investigación sobre la iglesia de San Pedro, enfocado en el estudio integral de su secuencia histórico-constructiva desde una perspectiva diacrónica. El presente artículo ofrece los primeros resultados de esta labor, en el cual serán objeto de análisis monográfico los vestigios más antiguos que se conservan del templo, pertenecientes a la primitiva construcción del siglo XIII.

\section{Breve síntesis histórica de la iglesia de San Pedro}

Teniendo en cuenta que San Pedro no ha sido nunca objeto de estudio parece necesario presentar antes una serie de breves apuntes que sirvan para establecer un adecuado encuadramiento histórico de esta iglesia enclavada en pleno centro del casco urbano de Íscar.

El primer testimonio documental de la iglesia se remonta al año 1247, al aparecer nombrada como Sant Petro y tributando "VII mrs. minus quartum" en el Plan de Distribución de Rentas del Cabildo Catedralicio de Segovia promovido por el cardenal Gil de Torres ${ }^{4}$, instrumento fiscal diocesano en el que también ya se hace alusión a las otras dos parroquias existentes en Íscar, Santa María y San Miguel. Si bien las tres advocaciones están presentes en este documento de mediados del siglo XIII, todo apunta a que San Pedro fuera la última de ellas en establecerse, pudiendo enmarcarse su construcción inicial en el contexto de los últimos impulsos repobladores que se fueron sucediendo en las campiñas meridionales del Duero, desde finales del siglo XII hasta bien entrado el siglo XIII, quizás hacia el final de esta horquilla temporal, estando integrada, al igual que las demás parroquias de la villa y tierra iscariense, en la diócesis de Segovia, sede a la que pertenecían desde el año $1123^{5}$.

A diferencia de las otras dos iglesias de Íscar, la céntrica ubicación de San Pedro (fig. 1) fue generando una vinculación cada vez más estrecha con el Concejo de Villa y Tierra. Así, en lo alto de su nueva torre se instalarán en 1590 la campana y el reloj de la villa ${ }^{6}$, en 1657 su sacristía se convierte en la sede del archivo de Villa y Tierra ${ }^{7}$, alcanzando esa simbiosis su punto más álgido a finales del propio siglo XVII, al quedar integrado San Pedro en el nuevo centro político-admi-

\footnotetext{
${ }^{1}$ Emplearemos el recurrente término "mudéjar" en vez de otros como "románico de ladrillo" o el más reciente de "albañilería románica", por razones operativas y por su arraigada implantación a la hora de designar a los diferentes ejemplos de este peculiar estilo arquitectónico en la comarca.

${ }^{2}$ Brasas Egido, 1977: 92-96.

3 Arranz Santos, 1995: 95-97, 175-176, 211, 263, 621-622 y 637. Aprovechamos para agradecer a Carlos Arranz Santos el apoyo prestado en la realización del presente trabajo, especialmente a través de sus valiosas aportaciones, precisiones y sugerencias.

4 Villar García, 1990: 203.

${ }^{5}$ Villar García, 1990: 51-52. Arranz Santos, 1995: 95-97.

${ }^{6}$ Arranz Santos, 1995: 211.

7 Arranz Santos, 1995: 211, nota 60.
}

Arch. esp. arte, LXXXVIII, 349, ENERO-MARZO 2015, 19-36 ISSN: 0004-0428, eISSN: 1988-8511, doi: 10.3989/aearte.2015.02 


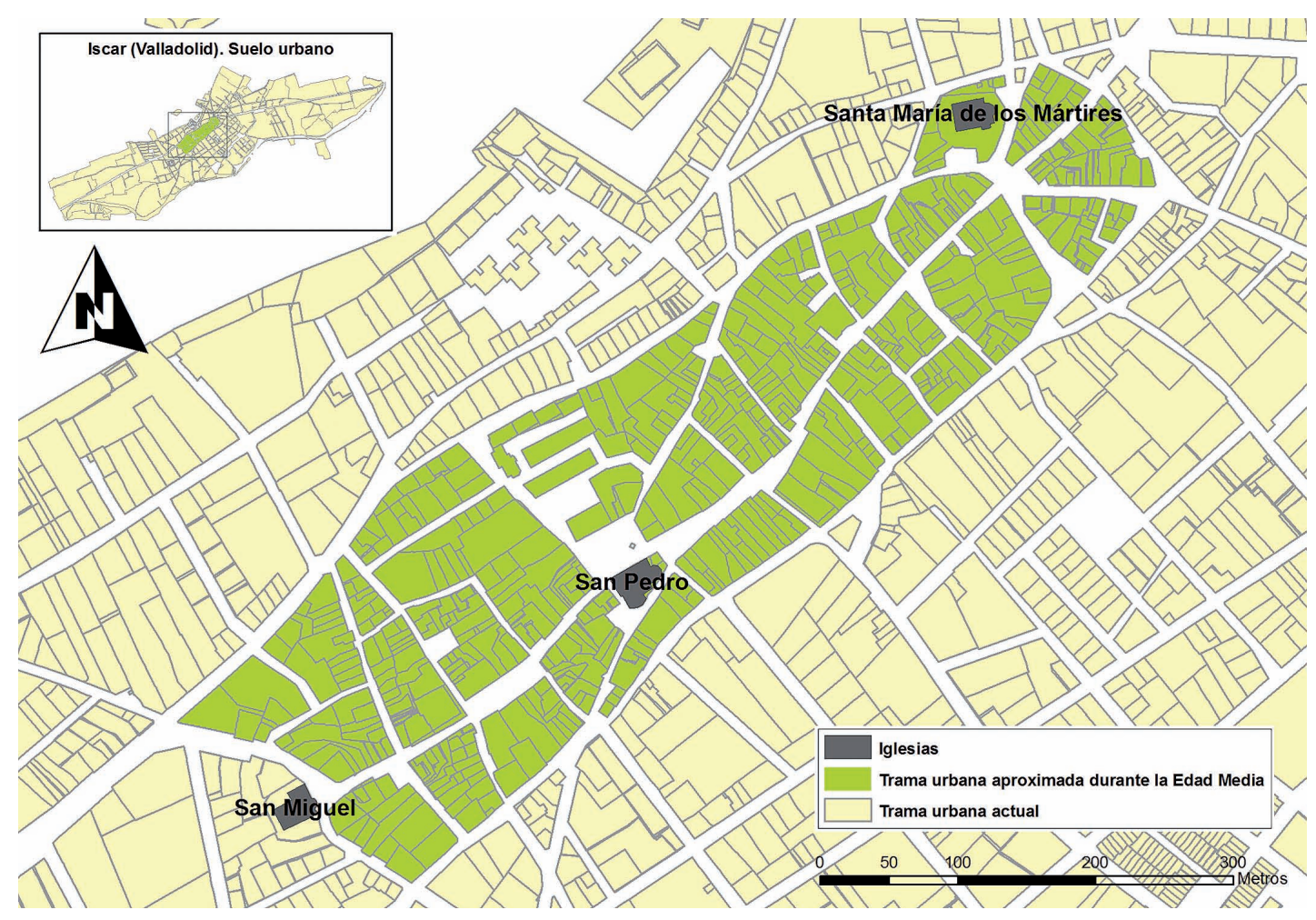

Fig. 1. Localización de las tres iglesias parroquiales de Íscar en el casco urbano medieval. Elaboración propia mediante S.I.G. a partir de cartografía de la D.G. del Catastro.

nistrativo de la localidad y de su Villa y Tierra, gracias al establecimiento de la Plaza de la Villa y a la construcción de una Casa de Consistorio de nueva planta en 1696, frente a la fachada norte del propio templo ${ }^{8}$.

Alcanzado el cénit, el ocaso de San Pedro se produce en los comedios del siglo XIX, a través de un sombrío proceso que pondrá punto y final a más de seis siglos de existencia, vinculado, como no podía ser de otra manera, a la convulsa etapa de desamortización de bienes eclesiásticos y reorganización parroquial vivida por nuestro país en aquel preciso momento histórico. En ese contexto el gobierno de Espartero emite un decreto sobre supresión de parroquias en la provincia de Segovia (1842), que, aunque en un principio establecía la agrupación de las iscarienses en torno a San Pedro ${ }^{9}$, llevará, sin embargo, a que Santa María de los Mártires se convierta de facto en la iglesia matriz de la villa en detrimento de aquella, debido probablemente a la arraigada mayor antigüedad de su advocación y al avanzado estado de ruina en el que se encontraba en aquel entonces la parroquial inicialmente elegida.

Tres cuartos de siglo después del cierre el arruinado edificio de culto es adquirido en 1925 por dos emprendedores iscarienses con el objeto de transformarlo en fábrica de harinas ${ }^{10}$. La readaptación para la actividad industrial conllevó una serie de drásticas reformas estructurales que afectaron pro-

\footnotetext{
${ }^{8}$ Arranz Santos, 1995: 208-210 y lám. IX.

9 Decreto del Regente de Reino de 30 de Mayo de 1842, B. O. P. de Segovia no 67 (07/06/1842), p. 2.

${ }^{10}$ Arranz Santos, 1995: 637.
}

Arch. esp. arte, LXXXVIII, 349, ENERO-MARZO 2015, 19-36 
fundamente al histórico edificio, salvándose solamente de la demolición aquellas estructuras vinculadas al concejo, caso de la torre, o susceptibles de reaprovechamiento, si bien siendo estas últimas cercenadas o enmascaradas. A lo largo del primer tercio del siglo XX, y en paralelo a este proceso de transformación de la iglesia, también fueron adosándose progresivamente al perímetro de su cabecera algunas viviendas, además de dos dependencias anexas a los pies del antiguo templo.

En agosto de 1934, la antigua torre, uno de los pocos restos supervivientes, se vio gravemente afectada por un incendio declarado en la fábrica, causando considerables daños en su estructura y provocando su demolición definitiva. El hecho de alojar aún el reloj y la campana de la villa de Íscar, los simbólicos elementos del Concejo de Villa y Tierra que secularmente habían presidido la plaza Mayor, llevó a un intento de restitución arquitectónica y de instalación de un nuevo reloj por parte del ayuntamiento, que finalmente resultó infructuoso ${ }^{11}$.

La fábrica de harinas echa el cierre de manera definitiva a mediados de los ochenta tras más de seis décadas de funcionamiento. Transcurridos casi treinta años desde el cese de la actividad industrial, el imponente edificio harinero heredero de San Pedro continúa impasible presidiendo la plaza Mayor de Íscar desde el sur (fig. 2), perteneciendo a otros propietarios, sin un uso definido y ante un futuro incierto. En compañía de las viviendas, comercios y anexos que se fueron adosando a su perímetro, conforma en la actualidad un caótico conglomerado de edificaciones que ocupa una manzana completa del centro urbano, en el que están insertos, y en un precario estado de conservación, los últimos restos pertenecientes a la antigua iglesia. En el extremo oriental se concentran las evidencias románicas, integradas por la cabecera de ladrillo, una estructura ahora más visible gracias al derribo a finales de 2012 de una de las viviendas que tenía adosadas ${ }^{12}$, y el

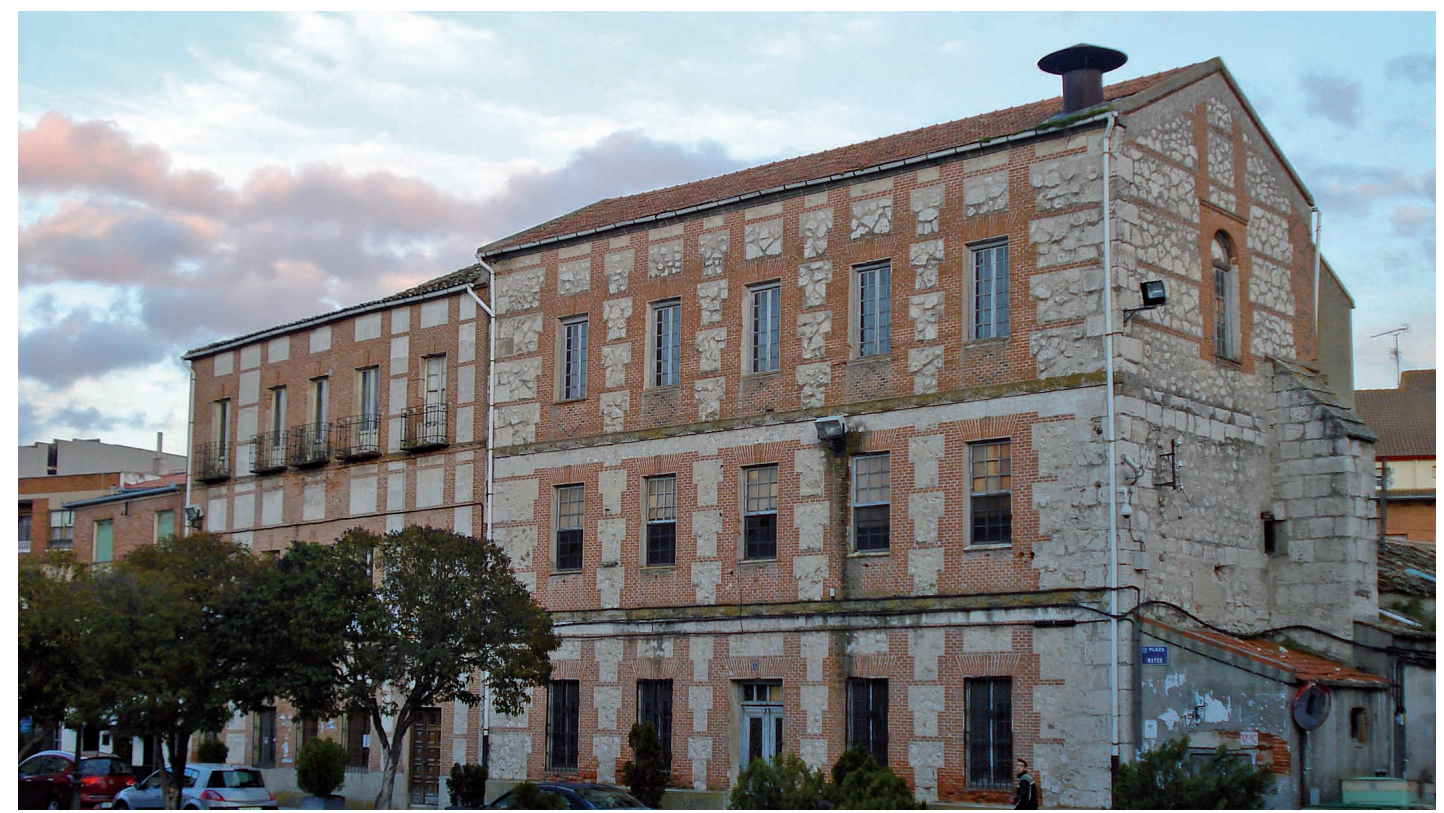

Fig. 2. Vista actual de la fachada norte de la fábrica de harinas desde la Plaza Mayor de Íscar. En el margen derecho se aprecia uno de los estribos de la antigua iglesia reaprovechados. Fotografía J. Esteban Molina.

\footnotetext{
${ }^{11}$ Arranz Santos, 1995: 637

12 Catalina Rico, 2013: 13.
}

Arch. esp. arte, LXXXVIII, 349, ENERO-MARZO 2015, 19-36 ISSN: 0004-0428, eISSN: 1988-8511, doi: 10.3989/aearte.2015.02 
testero oriental de la nave sur, descubierto a raíz de esa misma intervención. Por su parte, en el oeste perviven los posteriores restos de dos contrafuertes de sillería caliza situados originalmente a los pies de la iglesia, cuya construcción está documentada en el siglo XVI, además de una estancia con un potente paramento latericio que ocupa la esquina suroccidental.

\section{La construcción románica. Una aproximación arquitectónica}

La considerable nómina de estructuras desaparecidas a consecuencia de la acción transformadora y las adulteraciones de toda índole que presentan las evidencias conservadas hacen de todo punto imposible tener un conocimiento integral de lo que fue el planteamiento arquitectónico inicial de la iglesia de San Pedro, así como del alcance de muchas de sus posteriores reformas y ampliaciones. No en vano, estas circunstancias, como hemos señalado, han frenado cualquier tentativa de investigación y, en consecuencia, han reducido a la mínima expresión el corpus bibliográfico existente sobre la iglesia. Ante tal volumen de incógnitas irresolubles, nuestra modesta pretensión en el presente artículo, de partida, no podía ser otra que proceder a un análisis formal de los restos que han sobrevivido a las intensas transformaciones edilicias, en esta ocasión los románicos, aprovechando que desde hace escasas fechas son más patentes y que, sobre todo, aún permanecen inéditos para la investigación. Un análisis que se ha visto complementado por la información proveniente de algunas fuentes que, aunque parcas, han resultado ser sumamente útiles a la hora de esclarecer determinados detalles de esta fase constructiva, tanto de los restos conservados como de la arquitectura ya ausente en el edificio. En particular nos referimos a ciertas anotaciones de los libros de fábrica parroquiales entre los siglos XVI-XVIII y, sobre todo, a un breve e inédito informe sobre San Pedro incluido en un catálogo monumental de finales del primer tercio del siglo pasado, redactado poco antes de que la mayor parte del cuerpo de la iglesia, ya en ruinas, fuera irremisiblemente demolido ${ }^{13}$.

En consecuencia, el conocimiento obtenido mediante la conjunción de ambas metodologías ha sido tan fructífero que incluso nos va a permitir esbozar previamente, si bien de un modo somero, las líneas maestras de lo que pudo ser la estructura arquitectónica del edificio original, cuyo primer testimonio documental se remonta, como ya dijimos, al año 1247, una fecha que podemos considerar incuestionablemente como ante quem, y que, afinando un poco más, nos podría llevar a un momento de edificación inicial cercano a los años centrales de la primera mitad del siglo XIII, en función de un contexto histórico, socio-demográfico y económico sumamente propicio.

En la construcción de la iglesia de San Pedro se utilizó, de modo selectivo, un aparejo mixto de piedra y ladrillo, resultando abrumador el material latericio en la mayor parte de los restos conservados, del que es buena muestra la cabecera, aunque también está atestiguado el empleo de caliza, ya sea en forma de sillares (en el basamento del ábside y en el arranque y perfil del testero), mampuestos o calicanto (en el resto del alzado del testero), no pudiendo determinar con precisión el uso de cada uno de estos materiales en las restantes zonas de la iglesia más allá de lo que evidencian las estructuras supervivientes.

La iglesia, con orientación canónica, ya se debía articular mediante una planta de tres naves de la misma longitud y desigual anchura (fig. 3), generando un cuerpo principal de unas dimensiones globales y con una disposición muy similar a la que poseen sus convecinas de Íscar: Santa María de los Mártires y San Miguel, aspecto éste que pudiera revelar una más que probable compartimentación de sus naves en tres tramos, al igual que aquellas. La nave central, de mayor am-

13 Antón y Casaseca, 1927. Trabajo inédito compuesto de dos volúmenes. Al autor le fue asignada la provincia de Valladolid con fecha 10/07/1916. Una vez finalizado fue enviado a la Sección de Publicaciones del Ministerio de Instrucción Pública y Bellas Artes con fecha 10/02/1927. Existe una versión digitalizada en Internet: http://biblioteca.cchs.csic.es/digitalizacion_tnt/.

Arch. esp. arte, LXXXVIII, 349, ENERO-MARZO 2015, 19-36

ISSN: 0004-0428, eISSN: 1988-8511, doi: 10.3989/aearte.2015.02 


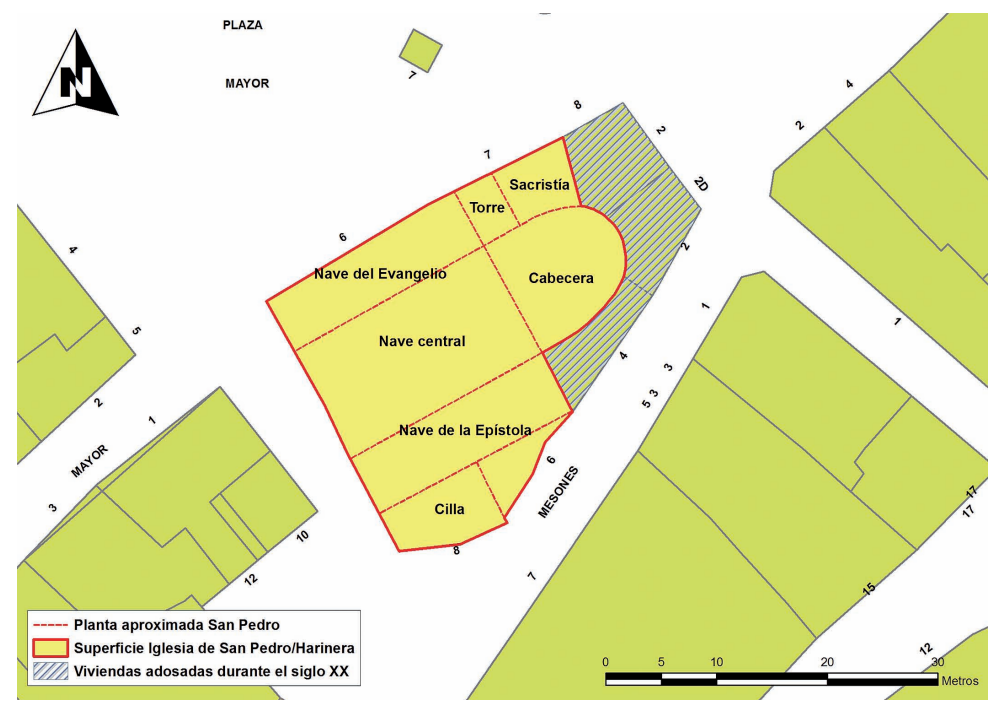

Fig. 3. Planta aproximada de la iglesia de San Pedro. El inmueble $n^{\circ} 4$ de la calle Mesones es el que ha sido demolido a finales de 2012. Elaboración propia mediante S.I.G. a partir de cartografía de la D.G. del Catastro.

plitud, se remataba mediante la cabecera de ladrillo conservada, compuesta de ábside y tramo recto presbiterial, ornamentada al interior y exterior con un programa arquitectónico y decorativo de clara raigambre mudéjar. Por su parte, las naves laterales se cerraban a oriente mediante testeros planos, de los que aún subsiste el de la nave de la Epístola. En función del reducido grosor que presenta este testero de cierre y de lo que se desprende de las fuentes documentales posteriores, las tres naves que constituían el cuerpo principal de la iglesia se debían cubrir en origen mediante una techumbre de madera, al igual que otras iglesias edificadas durante el mismo periodo, con parecida disponibilidad económica y, en consecuencia, con un similar planteamiento estético y constructivo. Esta armadura de madera fue objeto de periódicas reparaciones que constan en sus libros de fábrica, al menos desde comienzos del siglo $\mathrm{XVI}^{14}$, siendo finalmente sustituida en los inicios del segundo tercio del siglo XVIII ${ }^{15}$ por una cubierta de bóvedas tabicadas.

La torre se situaba al norte, ocupando el ángulo existente entre el testero de cierre de la nave del Evangelio y el tramo recto de la cabecera, una ubicación muy característica de la edilicia románica. Dicha torre suponemos que es la también documentada en los libros de fábrica parroquiales durante el segundo cuarto del siglo XVI ${ }^{16}$, poco antes de ser demolida y sustituida por otra de nueva construcción en $1554^{17}$. Aunque son constantes las alusiones tanto a la sacristía como a la cilla desde los primeros documentos parroquiales escritos, no podemos precisar si estos dos espacios ya formaban parte de la primitiva construcción. La sacristía se debió ubicar en el espacio existente entre la torre y el hemiciclo, siendo objeto de numerosas reformas y convirtiéndose con el paso de los años, tal como ya señalamos, en la sede del Archivo de la Comunidad de Villa y Tierra. Por su parte, la cilla tal vez sea el espacio reforzado con un recio paramento latericio ubi-

\footnotetext{
${ }^{14}$ Archivo General Diocesano de Valladolid (AGDV), Parroquia de San Pedro de Íscar (IPSP ${ }^{\circ}$ ), Cuentas de Fábrica (1527-1577), s/f. Brasas Egido, 1977: 93.

${ }_{15}$ Archivo Histórico Provincial de Valladolid (AHPV), Protocolos Notariales (PTN), leg. 10.518, f. 323 y ss. AGDV, IPSP ${ }^{\circ}$, Cuentas de Fábrica (1703-1755), cuentas de 1734-1736, f. 158v y cuentas de 1740-41, f. 182v. Brasas Egido, 1977: 96.

${ }^{16}$ AGDV, IPSP ${ }^{\circ}$, Cuentas de Fábrica (1527-1577), s/f.

${ }^{17}$ AGDV, IPSP', Cuentas de Fábrica (1527-1577), s/f. Brasas Egido, 1977: 93-94. La construcción de la torre del siglo XVI será objeto de estudio en próximos trabajos.
}

Arch. esp. arte, LXXXVIII, 349, ENERO-MARZO 2015, 19-36 ISSN: 0004-0428, eISSN: 1988-8511, doi: 10.3989/aearte.2015.02 
cado al suroeste del antiguo templo, cuya última reconstrucción se produjo en $1733^{18}$, siendo posteriormente reaprovechado en la fábrica de harinas con una funcionalidad similar, al utilizarse como almacén de grano ${ }^{19}$.

\section{La cabecera de San Pedro. Características y problemática cronológica}

De esta estructura románica tan solo se conserva hoy día, insistimos, la cabecera de ladrillo y el testero recto oriental de la nave de la Epístola, en ambos casos enmascarados en mayor o menor grado por los edificios que se fueron adosando en el extremo oriental del templo a lo largo del siglo XX.

Sobre el interior de la cabecera ya precisó algunos detalles F. Antón en su inédito Catálogo Monumental de la Provincia de Valladolid ${ }^{20}$, un autor que indudablemente pudo ver el arruinado interior de San Pedro en algún momento indeterminado entre 1916 (año en que es nombrado responsable de la elaboración del catálogo) y 1925 (inicio de la transformación de recinto eclesial en fábrica de harinas), ya que en la reseña que incluye sobre la iglesia en el trabajo finalmente entregado señala que "fue el templo de tres naves que hoy están completamente derruidas". En cualquier caso, una visita al interior de esta cabecera ${ }^{21}$ ha servido para contrastar las breves referencias proporcionadas por el erudito de origen zamorano, además de para identificar otros muchos elementos inéditos integrantes de la misma. Un interior que, como no podía ser de otra manera, dada la azarosa historia reciente del edificio, presenta en la actualidad un estado de conservación deplorable.

Según Antón, el acceso al presbiterio se realizaba a través de un arco triunfal de medio punto que "arrancaba de pilastras esquinadas y con impostas en nacela", dato que hemos podido confirmar, ya que aún se conserva el arranque de cuatro pilastras, aunque revocadas con cal, sobre las que se sustenta en el lado norte dicho arco (fig. 4). El presbiterio se cubría mediante una bóveda de medio cañón ${ }^{22}$, no visible en la actualidad debido a que una cubierta de madera ciega por completo toda la cabecera a la altura de la línea de imposta. Al igual que ocurre en otros templos pinariegos, este presbiterio se encuentra subdividido en dos tramos mediante la colocación de una pilastra adosada en cada uno de los lados, sirviendo ambas de apoyo a un arco fajón medianero ${ }^{23}$. En cada uno de los tramos resultantes se dispone un arco de medio punto doblado y ciego, con imposta de ladrillos en plantilla de nacela (fig. 5). En el lado norte de este tramo recto, a los pies del arco doblado oriental y cubierto bajo el enfoscado de cal, aún se aprecia buena parte del intradós de otro arco, que identificamos con el lucillo sepulcral del que ya informara Antón ${ }^{24}$.

Sendas pilastras de triple escalonamiento separan el ábside del presbiterio (fig. 6), sobre las que se debe apoyar con total seguridad el correspondiente arco de triple rosca que la cubierta de madera impide advertir. Ésta también oculta la bóveda de horno con la que se cubre el hemi$\operatorname{ciclo}^{25}$, tal como también se puede intuir al visualizar la estructura desde el exterior. En el semicilindro absidal se disponen tres grandes ventanas de medio punto, hoy día completamente ce-

\footnotetext{
18 AGDV. IPSP ${ }^{\circ}$. Cuentas de Fábrica (1703-1755), cuentas de 1733, f. 134v.

${ }^{19}$ Carrera de la Red, 1990: 87-88.

20 Antón y Casaseca, 1927: 326.

21 Queremos mostrar nuestro agradecimiento a la familia actual propietaria del edificio, en especial a Rubén Sansegundo, por las facilidades mostradas para poder visitar el interior de la antigua cabecera de la iglesia.

22 Antón y Casaseca, 1927: 326.

23 Antón y Casaseca, 1927: 326.

24 Antón y Casaseca, 1927: 326.

25 Antón y Casaseca, 1927: 326
}

Arch. esp. arte, LXXXVIII, 349, ENERO-MARZO 2015, 19-36

ISSN: 0004-0428, eISSN: 1988-8511, doi: 10.3989/aearte.2015.02 


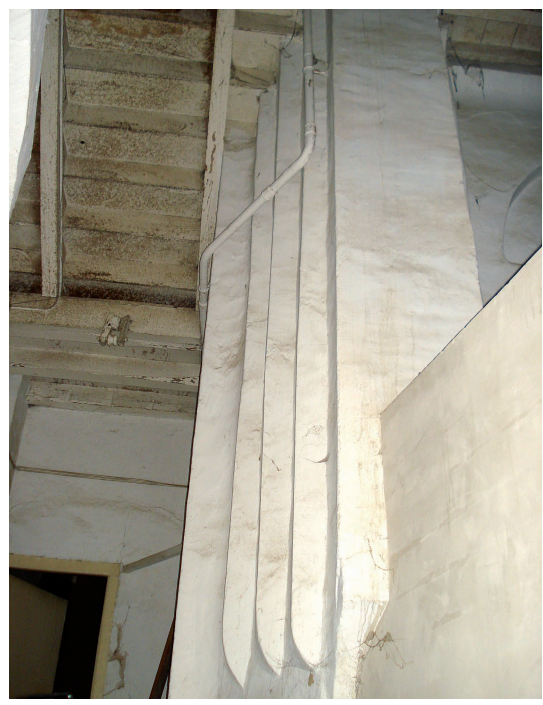

Fig. 4. Estado actual (bajo revocos) del arranque de las pilastras esquinadas del lado norte del arco triunfal. Iglesia de San Pedro, Íscar. Fotografía J. Esteban Molina.

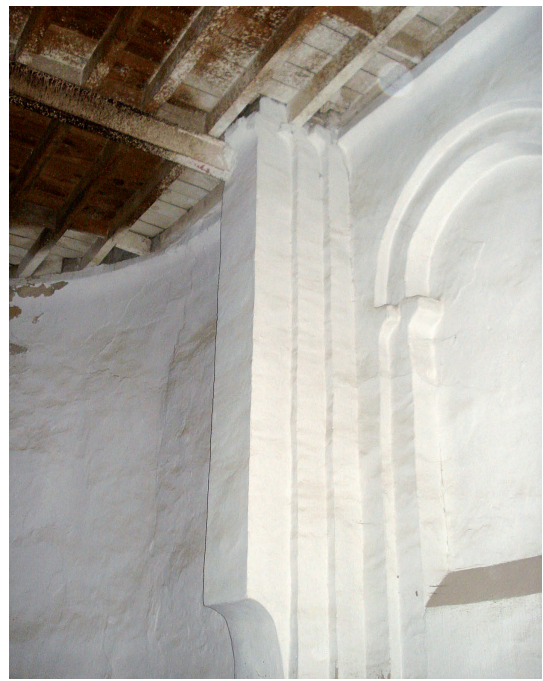

Fig. 6. Pilastra de separación entre el ábside y el presbiterio (lado sur). En la parte superior se aprecia la cubierta de madera que cubre todo la cabecera a la altura de la línea de imposta. Fotografía J. Esteban Molina.

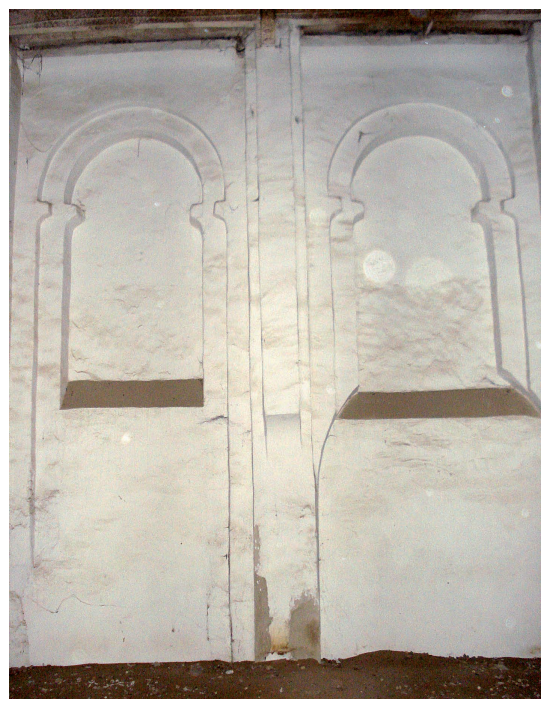

Fig. 5. Arcos ciegos doblados (bajo revocos) del tramo norte del presbiterio. En la parte inferior derecha se aprecia un vano identificable con el lucillo sepulcral referenciado por Antón. Fotografía J. Esteban Molina.

gadas (fig. 7), siendo la meridional incluso imperceptible a causa de los revocos posteriores, mientras que la septentrional se encuentra notablemente alterada a causa de la ubicación en esa zona del hemiciclo de un ulterior arcosolio, coronado mediante arco escarzano. Las dos roscas de ladrillo visibles de la ventana central, que pudieran ser más, confirman el ya acreditado carácter abocinado ${ }^{26}$ y con derrame interno de todas ellas, transformándose al exterior en las consabidas aspilleras que proporcionaban la iluminación de esta capilla mayor, de las que ha sido sacada a la luz recientemente la más meridional, a la altura del segundo cuerpo de arquerías (fig. 8).

Por encima de las ventanas una banda de ladrillos en nacela constituye la línea de imposta de la cabecera, localizándose bajo dicha banda lo que parece un friso de ladrillos en esquinilla, identificable, a pesar del recubrimiento de cal, gracias a la impronta dejada por las esquinas en el revoco a causa de la humedad, estando flan-

${ }^{26}$ Antón y Casaseca, 1927: 326; Carrera De La Red, 1990: 87.

Arch. esp. arte, LXXXVIII, 349, ENERO-MARZO 2015, 19-36 ISSN: 0004-0428, eISSN: 1988-8511, doi: 10.3989/aearte.2015.02 


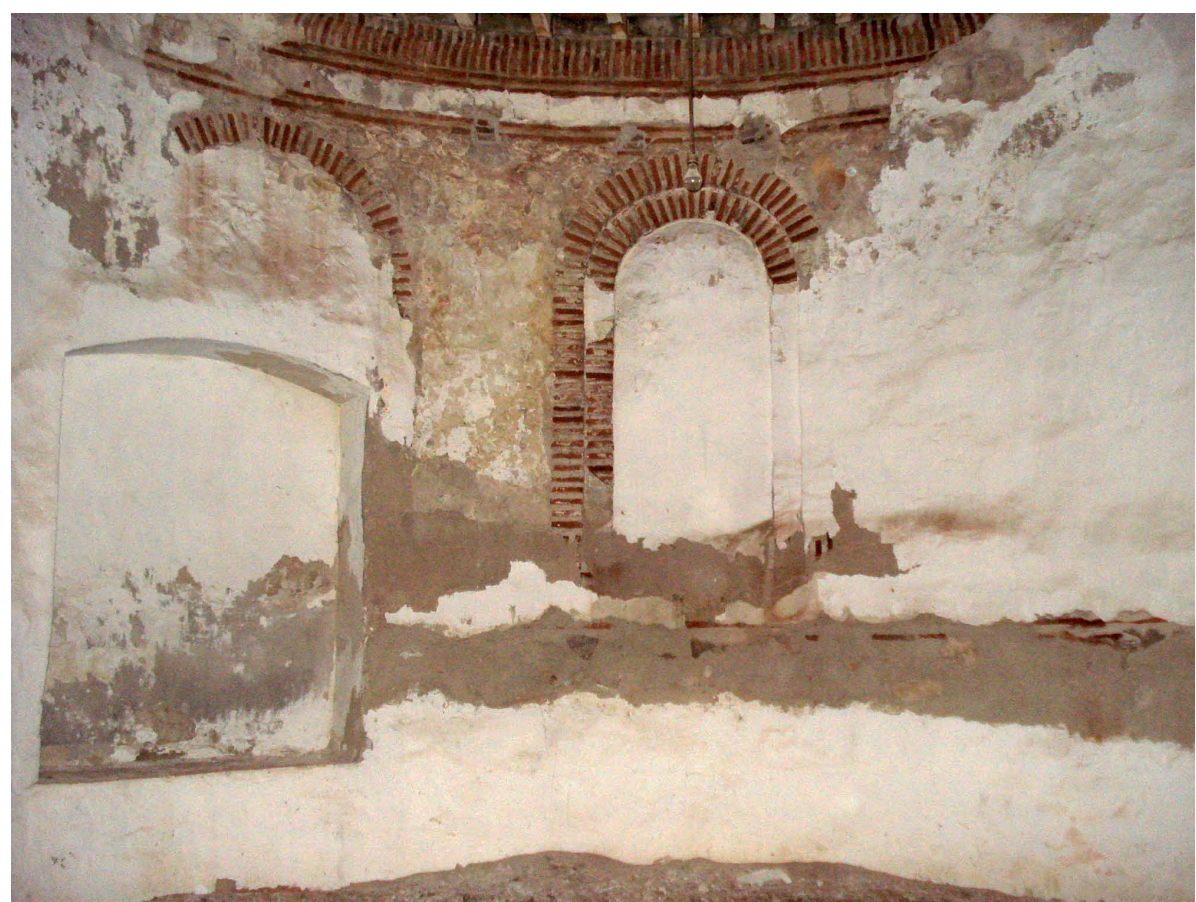

Fig. 7. Ventanas del interior del ábside de la iglesia de San Pedro. Fotografía J. Esteban Molina.

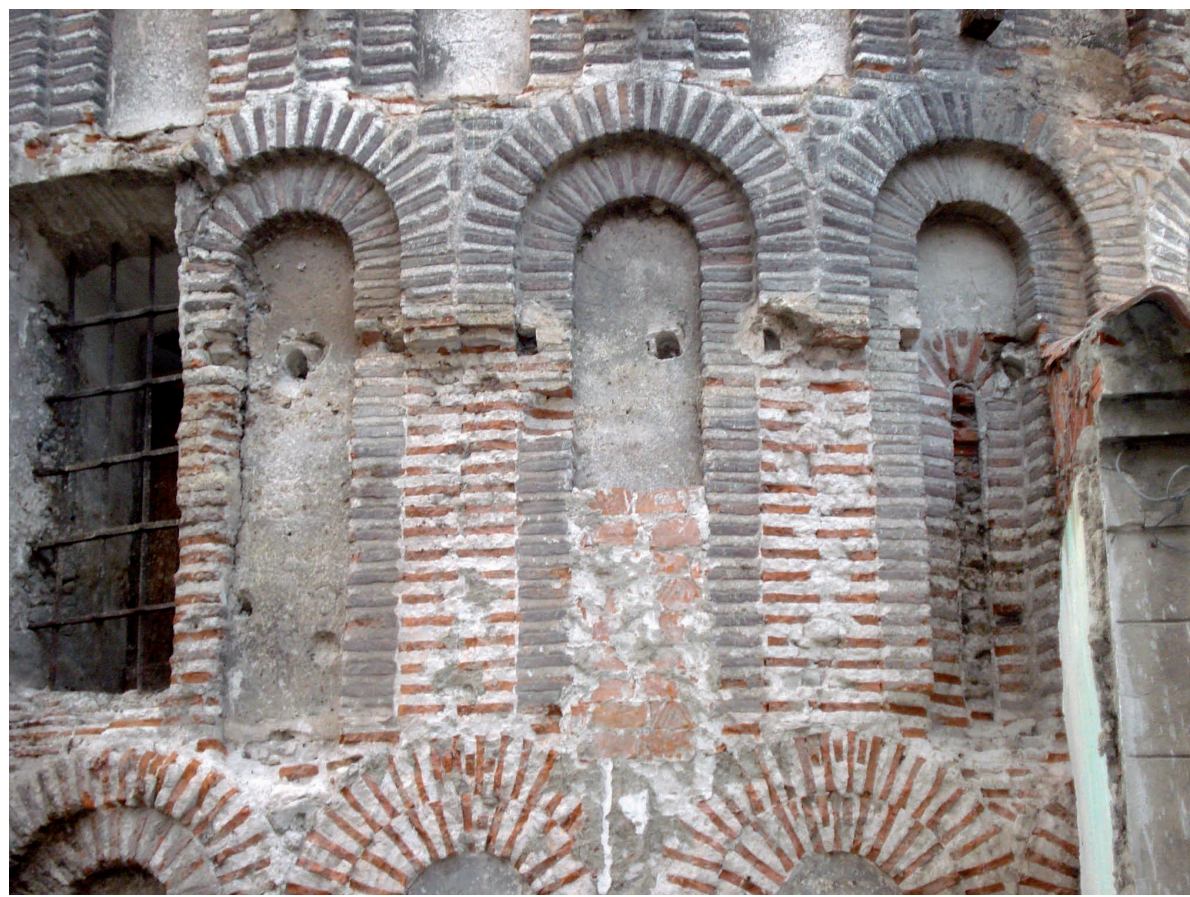

Fig. 8. Detalle de la aspillera (en el margen derecho) localizada en el exterior del ábside, puesta al descubierto a raíz de las obras de demolición de finales de 2012. Fotografía J. Esteban Molina.

Arch. esp. arte, LXXXVIII, 349, ENERO-MARZO 2015, 19-36

ISSN: 0004-0428, eISSN: 1988-8511, doi: 10.3989/aearte.2015.02 
queado por encima y por debajo con dos hiladas de ladrillos a soga. Del mismo modo, bajo el alféizar de los vanos tan solo se aprecia, y parcialmente, la existencia de otras dos hiladas a soga, sin que pueda advertirse la repetición del esquema decorativo en esquinilla localizado en la parte superior. Por último, también hay que señalar la presencia en la parte más septentrional del ábside de una pequeña puerta, hoy día sellada, que probablemente daría acceso a la sacristía.

En la configuración interior de esta cabecera se constatan, en suma, una serie de soluciones edilicias y ornamentales habituales en el mudéjar de la Tierra de Pinares. Así, la compartimentación del presbiterio en dos tramos articulados mediante arcos de medio punto doblados y ciegos apoyando sobre ladrillos en plantilla de nacela es una característica de San Pedro de Íscar que también se encuentra, aunque con arcos mucho más espigados, en San Martín de Cuéllar y San Baudilio de Samboal; de igual modo, sin estar apoyados en ladrillos nacelados, también encontramos arcos similares en los tramos rectos de San Pedro de Alcazarén, San Andrés de Olmedo, sin salir de la villa de Íscar, en Santa María de los Mártires y, ya en la actual provincia de Segovia, en Santiago de Cuéllar, Santa María de Águilafuente, San Esteban de Nieva y la ermita de San Mamés de Campo de Cuéllar, en este último caso bajo enfoscados ${ }^{27}$. Asimismo, entre San Pedro y la mayor parte de los ejemplares segovianos que hemos enumerado en uno u otro sentido existen evidentes analogías en cuanto a la simplicidad en la compartimentación y distribución de los elementos integrantes del semicírculo absidal ${ }^{28}$, a expensas de que futuras restauraciones puedan deparar sorpresas. En este sentido, en el templo iscariense se repite el esquema clásico de hemiciclo con dos cuerpos separados por bandas latericias corridas, en este caso con presencia de ladrillos en esquinilla solamente confirmada en la banda superior, tres ventanas abocinadas en el cuerpo superior y ausencia completa de ornamentación, tanto en los espacios de separación entre vanos como en el cuerpo inferior.

En el exterior, la cabecera de San Pedro se encontraba hasta hace pocos años prácticamente recubierta por los susodichos edificios adosados a su perímetro, pudiéndose advertir hasta finales de los ochenta, y en su parte superior, poco más que unas roscas de ladrillo correspondientes a la zona central del hemiciclo, algunos recuadros pertenecientes al tramo presbiterial sur, así como el alero que remataba todo este conjunto, siendo visibles todos estos elementos gracias a la menor altura que presentaban los edificios en esa parte de la manzana. El derribo en 1987 de la planta superior de una de esas viviendas ${ }^{29}$ dejó visibles cuatro arcos completos con un aspecto calamitoso en el último cuerpo de arquerías ciegas en la zona central del ábside. A finales de 2012 se produjo la consabida demolición de otro de los inmuebles en la zona meridional, poniendo al descubierto, también en un estado lamentable, el alzado completo del tramo recto presbiterial y una parte significativa del ábside (fig. 9).

Aún queda, sin embargo, mucho camino por recorrer en la mitad norte, donde la altura de una vivienda particular, sumada a la del antiguo bloque de oficinas anexo a la fábrica de harinas, en la actualidad fuera de uso, han provocado que en esa parte la cabecera se encuentre totalmente embebida en el interior de aquellos inmuebles (fig. 10). Pese a todo, esta intervención ha supuesto un importantísimo avance a la hora de profundizar en el conocimiento de esta pieza, debido a que el carácter seriado de los programas decorativos de la arquitectura mudéjar permite llevar a cabo una proyección ideal de todo el perímetro.

La exhumación ha permitido identificar el basamento de la cabecera, compuesto de varias hiladas de sillería caliza ${ }^{30}$, notablemente erosionadas en el tramo curvo. El ábside se compone de tres

\footnotetext{
${ }^{27}$ Moreno Blanco, 2007a: 422

${ }^{28}$ No entraría en esta consideración la iglesia de Santiago de Cuéllar, ornamentada con múltiples arcos ciegos en los dos cuerpos de su tambor absidal.

${ }^{29}$ Sánchez Merlo, 1987: 2.

${ }^{30}$ En 1675 están documentadas unas obras que parecen revelar una reparación del basamento en esta parte de la iglesia. AHPV, PTN, leg. 10.518, s/f.
}

Arch. esp. arte, LXXXVIII, 349, ENERO-MARZO 2015, 19-36 ISSN: 0004-0428, eISSN: 1988-8511, doi: 10.3989/aearte.2015.02 


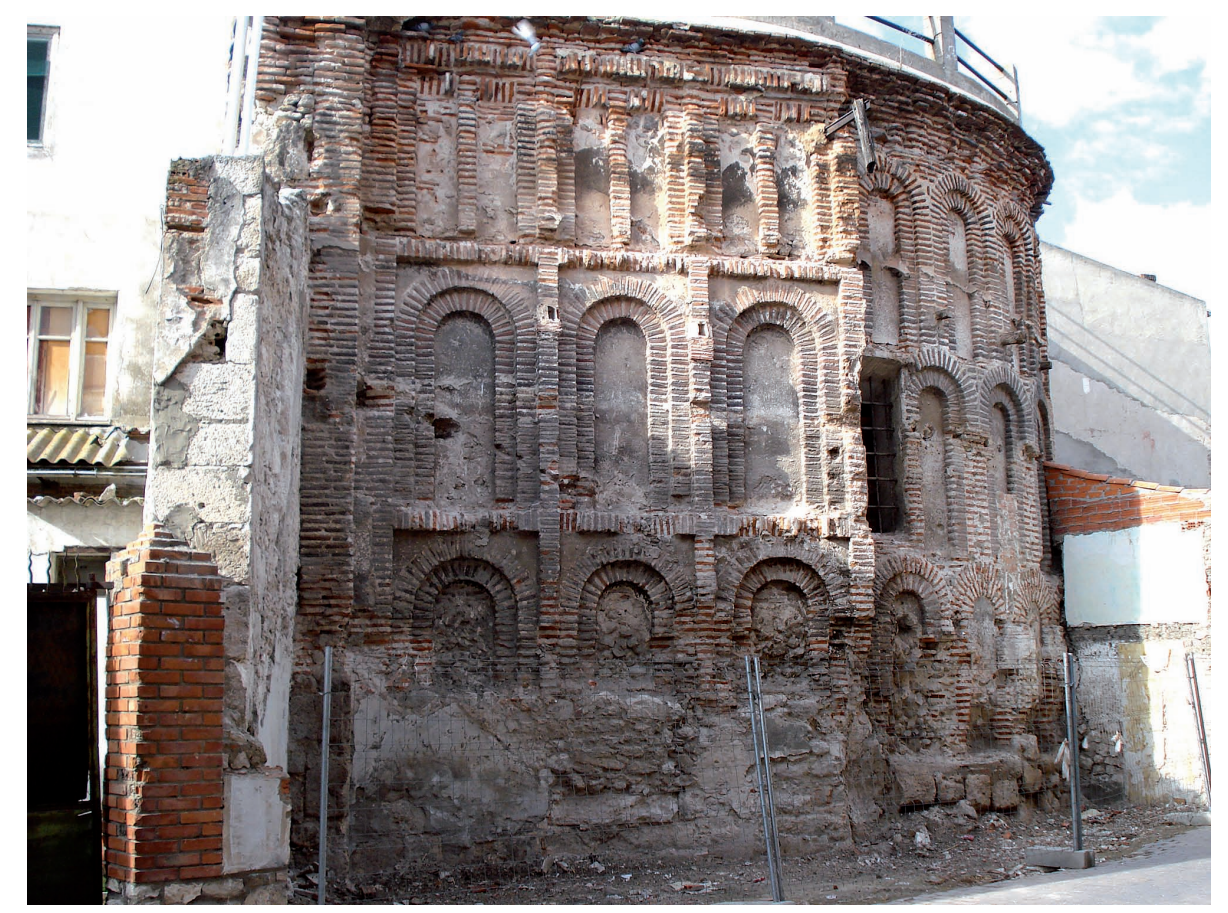

Fig. 9. Vista desde el sur del tramo de la cabecera de San Pedro recientemente sacado a la luz. Fotografía J. Esteban Molina.

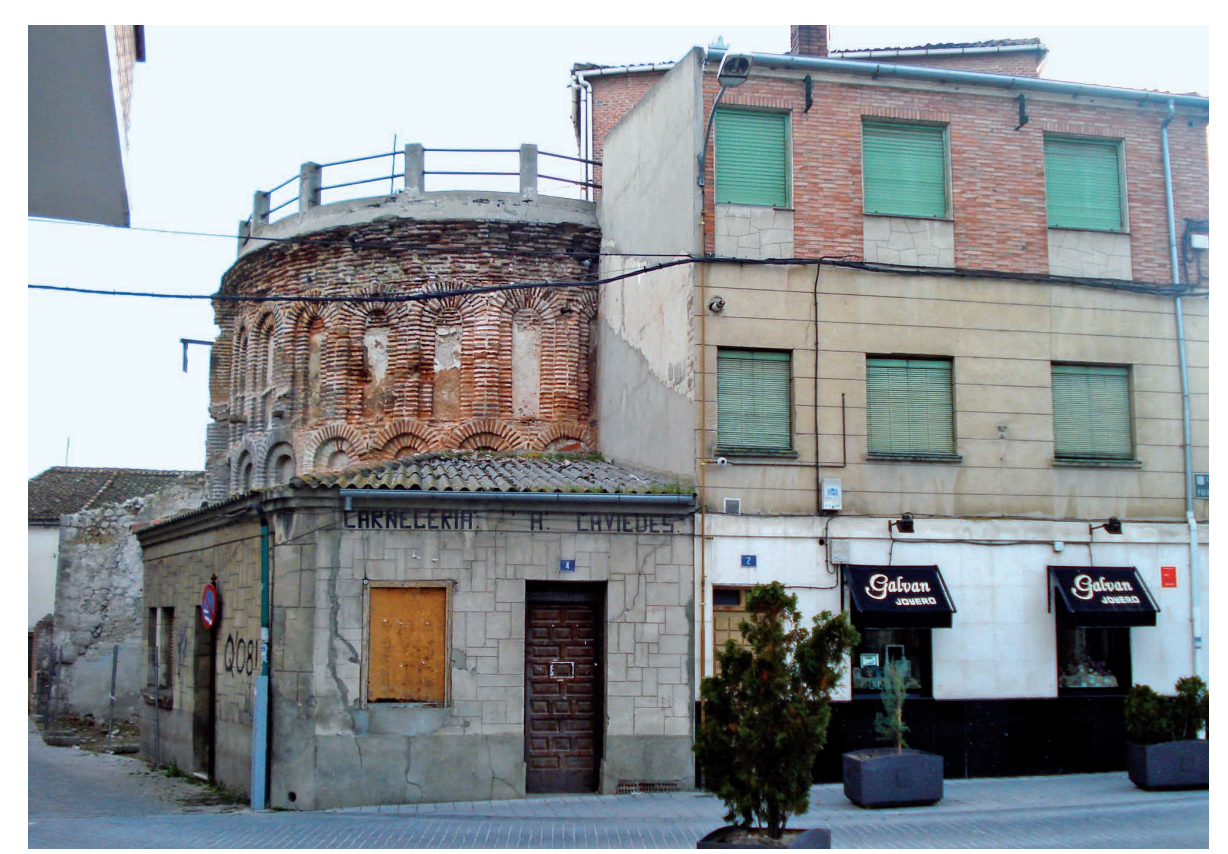

Fig. 10. Vista de la cabecera desde el este. En la imagen se aprecia como su mitad norte se encuentra actualmente embebida en un edificio de dos plantas y el bloque de oficinas de la fábrica de harinas. Fotografía J. Esteban Molina.

Arch. esp. arte, LXXXVIII, 349, ENERO-MARZO 2015, 19-36

ISSN: 0004-0428, eISSN: 1988-8511, doi: 10.3989/aearte.2015.02 
bandas superpuestas de arcos de medio punto doblados y ciegos, de similares proporciones ${ }^{31}$ y en posición desmentida. A pesar del nefasto estado de conservación se puede advertir que por encima de esta composición se disponían frisos de ladrillos en esquinilla individualizados, cada uno de ellos con el mismo ancho que el intradós de la primera rosca de los arcos doblados del cuerpo superior. El tramo recto presbiterial posee la misma altura que el hemiciclo aunque es ligeramente más ancho, prevaleciendo en él una trama reticular a modo de alfiz similar a la utilizada en San Pedro de Alcazaré ${ }^{32}$. Esa retícula en resalte cobija tres arcos de medio punto doblados y ciegos en cada uno de los dos primeros cuerpos, mientras que el tercero, que mantiene la anchura pero no la altura, es ocupado por tres rectángulos, subdivididos, a su vez, en otros dos más estrechos separados por una banda central, también latericia. Finalmente, toda la cabecera se corona mediante un alero conformado por cinco hiladas de ladrillos en saledizo, extremadamente dañados, sobre las que se sustentaba en su día el tejado, hoy día desaparecido y sustituido por una terraza moderna.

La descripción de esta estructura hasta ahora inédita permite establecer una serie de paralelismos. Una solución eminentemente estética que está presente en la cabecera de San Pedro, al igual que en otros muchos edificios del mudéjar pinariego segoviano y vallisoletano, es el empleo del tendel grueso, en ocasiones rebosante, en las junturas entre ladrillos, técnica empleada con el objeto de resaltar los efectos de la policromía ${ }^{33}$. Aunque con matices, también comparecen la mayor parte de las características estilísticas que definen el foco vallisoletano clásico que sistematizara Valdés a partir de San Pedro de Alcazarén ${ }^{34}$, lo que en la práctica, faculta a la iglesia homónima de Íscar para ser incluida en el grupo como un ejemplar más. Así, el apoyo de ábside y tramo recto sobre basamento, aunque en este caso con fábrica de sillería; la decoración mediante tres niveles o bandas de arquerías superpuestas, si bien con diferencias de canon casi inapreciables entre las bandas de nuestro ejemplar iscariense; la no alineación de los arcos de las tres bandas del ábside en vertical respecto a un mismo eje de simetría; el empleo de la retícula en resalte en el tramo recto, en el caso iscariense con tres fajas en vertical; y por supuesto, la coronación mediante un friso de ladrillos en esquinilla.

Pero por encima de todo, las características expuestas a la luz de la reciente exhumación de esta parte de la cabecera de San Pedro arrojan como resultado más significativo algo que ya podía intuirse antes de la demolición del inmueble: la existencia de un planteamiento decorativo externo cuasi idéntico al de su convecina de Santa María de los Mártires (fig. 11), por otra parte, ésta también integrante del foco vallisoletano ${ }^{35}$. Buen ejemplo de la afinidad entre ambas es el empleo de casetones o rectángulos pareados de similar traza en los tramos superiores de la retícula de sus tramos rectos, con la particularidad añadida de que esta solución no es aplicada en el último cuerpo del ábside de los dos templos iscarienses, a diferencia de lo que ocurre en los demás ejemplos conocidos en la comarca, con independencia de sus variaciones de diseño: San Andrés, San Esteban y San Martín de Cuéllar ${ }^{36}$, la ermita de San Mamés de Campo de Cuéllar ${ }^{37}$, además de San Miguel de Olmedo ${ }^{38}$ y Santa María de Mojados ${ }^{39}$, integrantes las dos últimas de la fase manierista vallisoletana. Con todo ello, las únicas diferencias observables se limitan al apoyo de la fábrica de ladrillo, sobre sillería en

\footnotetext{
${ }^{31}$ En total deben ser doce arcos, una vez hecha la proyección ideal.

32 Valdés Fernández, 1981: 105-106 y 183-184.

33 Pérez Higuera, 1993: 62.

34 Valdés Fernández, 1981: 183-184.

35 Valdés Fernández, 1981: 192-193; 2007, p. 92.

${ }^{36}$ Gil Farrés, 1950: 97-99. Santamaría López, 1973: 454, 456 y 457. Ruiz Hernando, 1988: 66, 68 y 70. Moreno Blanco, 2007c: 582 y 584; 2007d: 593; 2007e: 597.

${ }^{37}$ Moreno Blanco, 2007a: 420.

${ }^{38}$ Valdés Fernández, 1981: 201; 1996: 125; 2007: 94.

39 Valdés Fernández, 1981: 205; 1996: 128; 2007: 92.
}

Arch. esp. arte, LXXXVIII, 349, ENERO-MARZO 2015, 19-36 ISSN: 0004-0428, eISSN: 1988-8511, doi: 10.3989/aearte.2015.02 


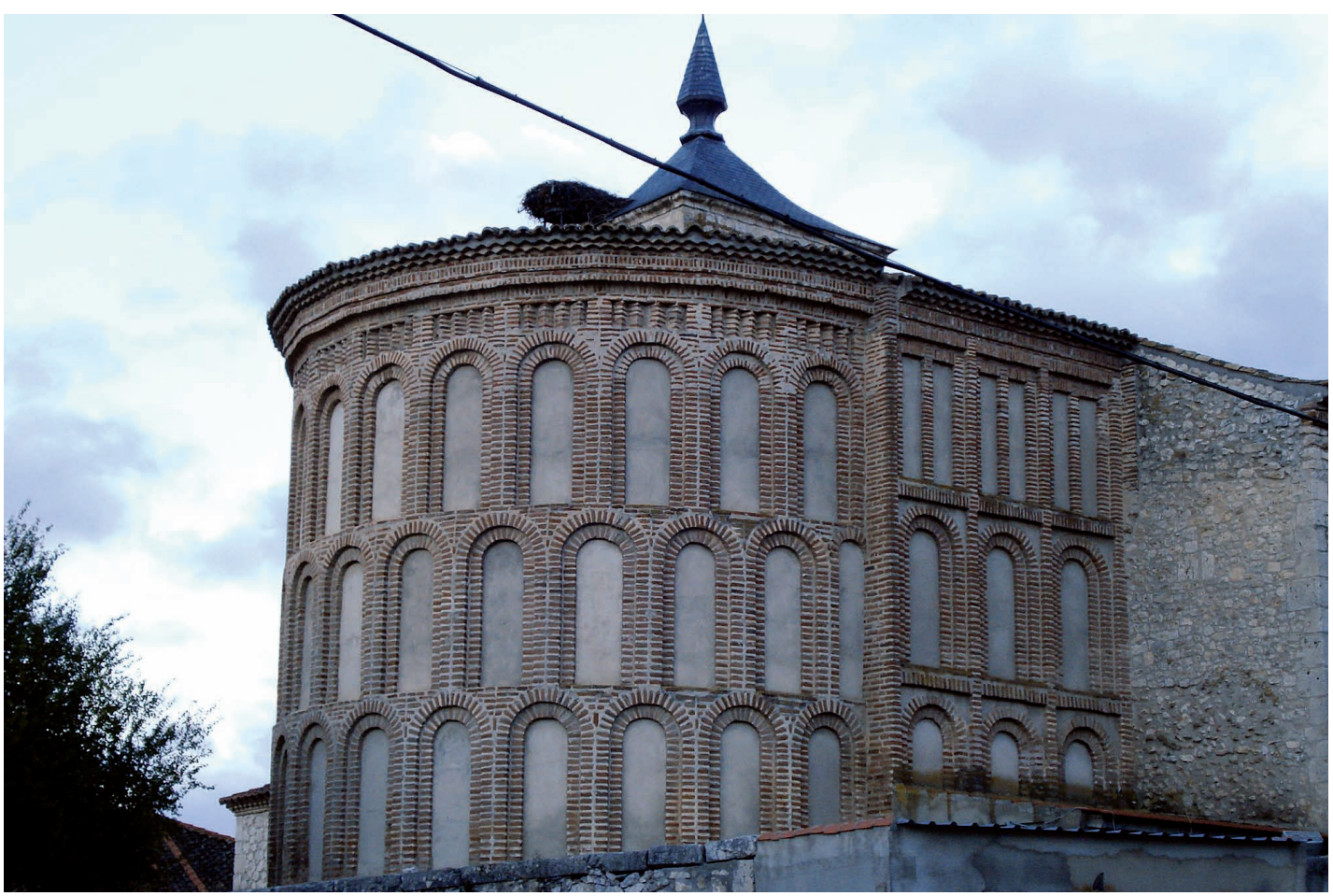

Fig. 11. Cabecera de la iglesia de Santa María de los Mártires, Íscar. Fotografía J. Esteban Molina.

San Pedro y sobre un aparejo mixto de sillería y mampostería en Santa María, la indiscutible menor altura que presenta la cabecera de la primera, lo que lleva, en consecuencia, a un canon más reducido de sus tramos de arquerías exteriores respecto a la segunda, y por último, la divergencia en los remates de los aleros, ya que, mientras en San Pedro se opta por cinco hiladas de ladrillos volados para ábside y presbiterio, en la iglesia matriz de Íscar se aplica una solución más compleja: el alero del hemiciclo se compone de una banda a sardinel apoyada sobre otra de ladrillos aplantillados en nacela y en el tramo recto esta cuestión se zanja mediante la superposición de dos sardineles ${ }^{40}$.

En suma, son tantas sus similitudes y tan circunstanciales sus diferencias que se hace difícil no pensar en una ejecución llevada a cabo por un mismo taller, y posiblemente de un modo, si no sincrónico, al menos bastante cercano en el tiempo. En este sentido, el menor canon y, sobre todo, la traza totalmente semicircular del ábside de San Pedro quizás pudiera determinar una mayor antigüedad en su favor, ya que en el caso de Santa María, aunque existe una disposición similar, el hemiciclo realmente está conformado mediante doce bandas o paños verticales que generan un perímetro absidal cuasi poligonal, solución ésta que, aunque ya es utilizada de un modo más descarado en algunas cabeceras de otros focos castellano-leoneses durante la denominada fase clási$\mathrm{ca}^{41}$, en el caso de Íscar nos parece evolucionada respecto al perímetro completamente semicir-

${ }^{40}$ Fruto de la profunda restauración que se acometió en el templo en 1978. En fotografías anteriores a esa fecha se observa, al igual que en San Pedro, la existencia de varias hiladas de ladrillos en saledizo apoyadas sobre los ladrillos en nacela del ábside y sobre el primer sardinel del tramo recto. Véase Antón y Casaseca, 1927: lám. C.

${ }^{41}$ Por ejemplo en las iglesias de San Lorenzo de Toro (Zamora) o San Feliz de Saelices del Río (León) en el foco de Sahagún. Véase Valdés Fernández, 1981: 157 y 161.

Arch. esp. arte, LXXXVIII, 349, ENERO-MARZO 2015, 19-36

ISSN: 0004-0428, eISSN: 1988-8511, doi: 10.3989/aearte.2015.02 
cular, pudiendo haber influido, junto con la técnica de aplicar recuadros y casetones en los últimos cuerpos, en el diseño de las de San Martín, San Andrés y San Esteban de Cuéllar, aspecto éste último ya apuntado por Valdés ${ }^{42}$.

A la hora de establecer una cronología para esta estructura inédita no podemos obviar la datación que ofrece el primer testimonio documental sobre la iglesia de San Pedro, del año 1247. Una datación que resulta, sin embargo, ciertamente temprana a la hora de ceñirnos a la cabecera, a tenor de la cronología establecida para este tipo de estructuras integrantes del llamado foco vallisoletano, cuyo momento inicial se sitúa en la segunda mitad e incluso finales del siglo XIII, en base a las pinturas murales de San Pedro de Alcazarén ${ }^{43}$, y en el que la cabecera de Santa María de los Mártires es uno de los ejemplos más tardíos, al ser fechable en los años finales del siglo XIII o principios del XIV ${ }^{44}$, a caballo entre las fases clásica y manierista. Teniendo en cuenta que la cabecera de Santa María es contemporánea o, como mucho, ligeramente posterior a la de San Pedro, en función de los pormenores anteriormente expuestos, el momento de construcción más temprano de esta última nos llevaría, como muy pronto, a los postrimeros años del siglo XIII, un momento que, insistimos, sobrepasaría en todo caso los límites de la fecha ante quem establecida para todo el edificio.

Ante esta tesitura, lo indicado sería aceptar de buen grado la cronología de la cabecera de Santa María, y pensar, por tanto, que la de San Pedro es obra de finales del XIII, considerando así a ambas como fruto de reformas o ampliaciones posteriores en los edificios documentados en 1247. Sin embargo, el hecho de que idéntica explicación se tendría que repetir miméticamente, y sin excepción alguna, si aplicáramos este mismo discurso a cada una de las cabeceras de las iglesias del mudéjar de Cuéllar, integradas en ese preciso momento en el obispado segoviano, al igual que las iscarienses, hace que mantengamos nuestras reservas al respecto.

En efecto, las iglesias cuellaranas también están perfectamente documentadas en el Plan de Distribución de Rentas del obispado de Segovia ${ }^{45}$, un conjunto arquitectónico para el que además buena parte de la investigación ha establecido unas fechas concomitantes con la del propio documento, sin vislumbrarse en ningún caso una distinción cronológica entre cabecera y el resto del edificio románico. Sin ir más lejos, Ruiz Hernando incluye a todos los ejemplares del mudéjar cuellarano en su trabajo sobre el románico de ladrillo del siglo XIII en la provincia de Segovia $^{46}$, Martín González sitúa a la iglesia de San Esteban de Cuéllar, e incluso a Santa María de Íscar, dentro de ese mismo siglo ${ }^{47}$, para Yarza el mudéjar cuellarano, con San Andrés a la cabeza, es de finales del siglo XII y primera mitad del XIII ${ }^{48}$, López Guzmán, también engloba a las iglesias de Cuéllar en esta misma centuria ${ }^{49}$, y por último, Moreno Blanco, en fechas más

${ }^{42}$ Valdés Fernández, 1981: 193.

${ }^{43}$ Valdés Fernández, 1981: 184; 2007: 90. Es en el segundo trabajo donde Valdés lleva San Pedro de Alcazarén a finales del siglo XIII. En cualquier caso, esta cronología, sustentada en las desaparecidas pinturas murales de su ábside, de amplio e impreciso espectro temporal en función de las distintas propuestas de los expertos, debería ser objeto de revisión, cuando no de replanteamiento. No debemos pasar por alto que los frescos, cuando quiera que fueran ejecutados, se proyectaron sobre un paramento en cuyo diseño y construcción se percibe una clara intención estética y de perdurabilidad, como pone de manifiesto el armónico trabajo en ladrillo de la fábrica original sacado a la luz a raíz de los trabajos de restauración de 1999-2000, del que son buen ejemplo las tres bandas superpuestas en esquinilla que recorren los espacios situados entre las ventanas abocinadas, precisamente los mismos sobre los que se dispusieron las escenas figuradas de las postreras pinturas murales.

${ }^{44}$ Valdés Fernández, 1981: 192; 1996: 122; 2007: 91-92. En el último trabajo Valdés la califica como del siglo XIV.

${ }^{45}$ Se trataría de San Andrés, San Esteban, San Martín, El Salvador y Santa Marina, junto con otras del románico de piedra de la localidad. Aunque no aparece en ese documento diocesano la iglesia de Santiago de Cuéllar, sí se tiene constancia de su existencia en otro de 1244.

${ }^{46}$ Ruiz Hernando, 1988: 65-70 y 77.

${ }^{47}$ Martín González, 1982: 414.

48 Yarza Luaces, 2004: 320-321.

49 López Guzmán, 2000: 217-219.

Arch. esp. arte, LXXXVIII, 349, ENERO-MARZO 2015, 19-36 ISSN: 0004-0428, eISSN: 1988-8511, doi: 10.3989/aearte.2015.02 
cercanas, ha establecido unas dataciones para estos ejemplares que oscilan entre finales del siglo XII y primera mitad del XIII ${ }^{50}$.

Por contra, Valdés dictamina para las cabeceras cuellaranas una cronología que oscilaría entre los siglos XIV y XV ${ }^{51}$, e incluso más recientemente el $\mathrm{XVI}^{52}$, unas fechas extremadamente distantes respecto a la data del documento fiscal diocesano y a las establecidas por los autores citados, generando, a nuestro modo de ver, una discordancia que, al igual que en Íscar, forzaría en Cuéllar un escenario en el que no cabría otra posibilidad que separar cabeceras mudéjares de edificios y considerar absolutamente a todas las conservadas, pese a pertenecer a iglesias constatadas a mediados del XIII, como producto de reformas de albañilería posteriores y no como parte integrante de los templos originales.

En medio de este panorama es la arqueología la disciplina que puede arrojar más luz al respecto, puesto que ha deparado en fechas recientes unos resultados que parecen descartar la hipótesis planteada y, a su vez, establecer un escenario más plausible. Así, durante la intervención arqueológica llevada a cabo en el año 2005 en la iglesia de San Esteban de Cuéllar ${ }^{53}$ se practicaron diversos sondeos en el perímetro e interior del templo, determinando que la cimentación del edificio, cabecera incluida, correspondía a comienzos del siglo XIII ${ }^{54}$, no documentándose en el solar otras estructuras arquitectónicas, ni anteriores ni posteriores. Esta datación quedó además reforzada por la identificación en el entorno inmediato del templo de una fase de uso funerario, de las tres existentes, caracterizada por la presencia de una serie de enterramientos formados por hileras horizontales de ladrillo macizo entre tendeles de argamasa de cal y arena, con una adscripción cultural que viene a corresponder con el siglo XIII, en consonancia con otras necrópolis coetáneas excavadas al sur del Duero, sincrónicas además con la fábrica de los templos mudéjares en cuyas inmediaciones se disponen ${ }^{55}$. En definitiva, esta actuación arqueológica proporcionó una datación más temprana, que resulta pareja a las de otras intervenciones en contextos temporales similares, en la que se da cabida a la cabecera y que, además, es sustancialmente coincidente con las fechas propuestas por el grupo de investigadores ya citado.

A tenor de todas estas consideraciones, y teniendo en cuenta la anterioridad de las cabeceras del mudéjar iscariense respecto a San Esteban, en función del carácter evolucionado que presentan las soluciones decorativas aplicadas en el ábside cuellarano, o en todo caso una cierta contemporaneidad, podríamos pasar a hablar de unas fechas análogas, comienzos del siglo XIII, o quizás de su segundo cuarto, para la construcción de San Pedro y Santa María de Íscar ${ }^{56}$, por tanto en un momento anterior a la fecha ante quem que manejamos, y plenamente compatibles con ella, considerando por supuesto a las cabeceras como parte integrante de los edificios originales, al igual que en San Esteban. Eso sí, con la única salvedad de que en el caso de la cabecera de Santa María estaríamos forzosamente ante una estructura superviviente de una edificación de nueva planta que nada tiene que ver con el edificio documentado a finales del $\mathrm{XI}^{57}$, en función del más que evidente desfase anacrónico existente entre esa prematura fecha y las características arquitectónicas y or-

${ }^{50}$ Primera mitad del siglo XIII para El Salvador, Moreno Blanco, 2007b: 575. San Andrés, siguiendo a Yarza, finales del siglo XII y primera mitad del XIII, Moreno Blanco, 2007c: 576. San Esteban la considera construida en 1247, Moreno Blanco, 2007d: 587. San Martín, primer tercio del siglo XIII, Moreno Blanco, 2007e: 598.

51 Valdés Fernández, 1996: 116.

${ }^{52}$ Valdés Fernández, 2007: 93.

${ }^{53}$ Enmarcada en el proyecto de restauración integral del templo, promovido por la Fundación del Patrimonio Histórico de Castilla y León. Véase Palomino Lázaro et alii, 2011.

${ }^{54}$ Aratikos Arqueólogos, 2005: 28. Informe técnico depositado en la sede de la Fundación del Patrimonio Histórico de Castilla y León (inédito).

${ }^{55}$ Palomino Lázaro et alii, 2011: 32

${ }^{56}$ Nuño González, aun aceptando las fechas de Valdés para la cabecera de Santa María de los Mártires, abre la posibilidad de que su construcción se remonte, al menos, a mediados del siglo XIII. Véase Nuño González, 2002: 225.

${ }^{57}$ Mañueco Villalobos y Zurita Nieto, 1917: 11-16.

Arch. esp. arte, LXXXVIII, 349, ENERO-MARZO 2015, 19-36

ISSN: 0004-0428, eISSN: 1988-8511, doi: 10.3989/aearte.2015.02 
namentales de la fábrica conservada, supuesto éste que deberá ser esclarecido a través de futuras intervenciones arqueológicas en el entorno del edificio.

Al hilo de esta cuestión y sin pretender, en modo alguno, poner en tela de juicio la impecable sistematización y evolución de la arquitectura mudéjar desarrollada por Valdés a lo largo de los últimos años, será precisamente la arqueología la que en el futuro juegue un papel fundamental a la hora de calibrar las dataciones de los templos, tanto a título individual, San Pedro incluido, como a nivel global, proporcionando el compendio de datos necesario para determinar si es factible una revisión de las cronologías, que no la evolución estilística, de las cabeceras que integran los denominados focos clásico y manierista vallisoletano, así como refrendar la del conjunto mudéjar cuellarano, que en el caso particular de San Esteban ha quedado, creemos, suficientemente demostrada.

\section{El testero de cierre oriental de la nave de la Epístola}

Este elemento fue sacado a la luz a raíz de la señalada demolición (fig. 12). Constituye aún el muro de cerramiento oriental del patio que antecede al antiguo muelle de carga de la harinera, aunque había pasado desapercibido hasta la fecha debido a las sucesivas capas de enfoscado aplicadas en su visible superficie occidental, sin olvidar la presencia de la vivienda a oriente, los efectos de ciertas restituciones poco afortunadas y una deformación más que palmaria. Por tanto, ha tenido que ser la cara oriental de este lienzo, descubierta tras el derribo, la que nos muestre sus características constructivas, si bien cubierta aún con restos de los revestimientos pertenecientes a los ambientes interiores del inmueble hasta hace poco adosado.

El alzado de este testero resulta sumamente expresivo a pesar de su penoso estado de conservación. Presenta un grosor de apenas $60 \mathrm{~cm}$. (lo que equivaldría a dos pies castellanos), siendo posiblemente el último exponente y el mejor indicador de lo que pudo ser la primitiva estructura muraria perimetral del cuerpo de la iglesia, extremadamente endeble y con todos los visos de haber sido planteada en origen para soportar una cubierta lígnea. Se dispone perpendicularmente a la cabecera, uniéndose a ella a la altura del engrosamiento del borde occidental del tramo recto que actúa a modo de separación entre este y el cuerpo principal de la iglesia. El lienzo alcanzó en su día una altura ligeramente superior a la actual, a tenor del evidente rebaje que presenta en la parte superior y de la impronta dejada en el encuentro con el propio tramo presbiterial. Pese a esta mutilación, vinculada al proceso de reutilización de este elemento, se pone claramente de manifiesto la menor altura de esta nave meridional respecto a la central, un

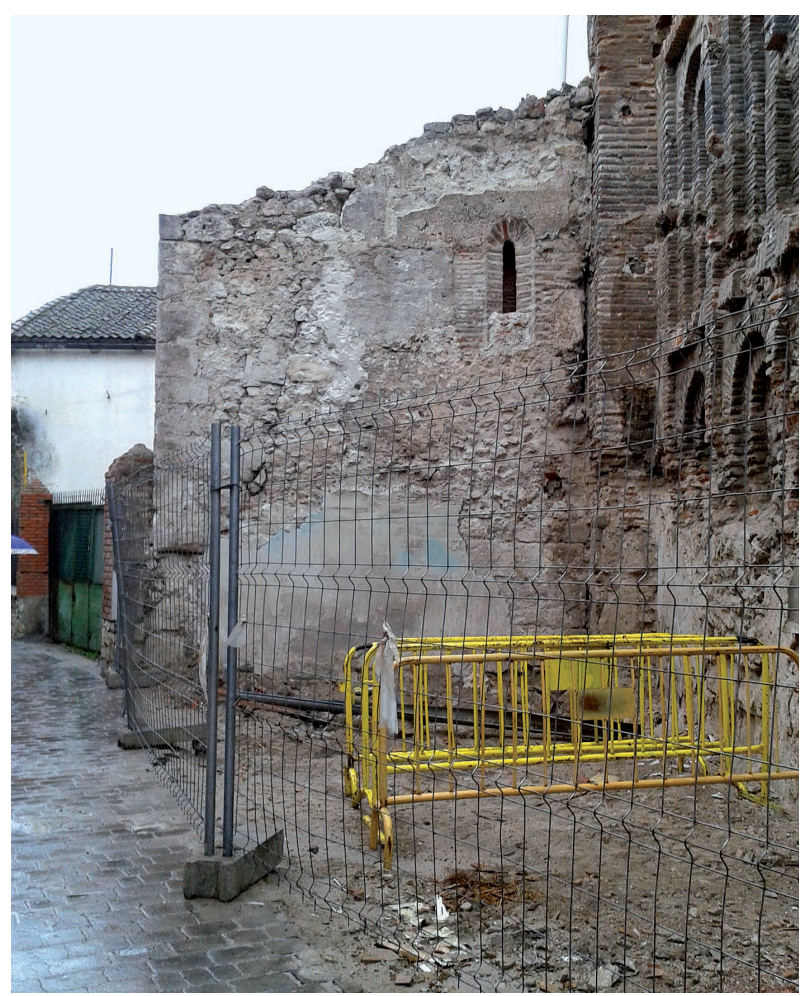

Fig. 12. Testero de cierre oriental de la nave de la Epístola, descubierto tras la demolición del inmueble adosado. Fotografía J. Esteban Molina. 
rasgo que también está documentado, como veremos en posteriores trabajos, en el caso de la del Evangelio.

En cuanto al aparejo, se empleó una fábrica mixta de sillería y mazonería, en ambos casos de caliza pontiense, disponiéndose sillares a modo de refuerzo lateral en el borde, con signos claros de restitución contemporánea, y en las tres hiladas superpuestas que constituyen la base, mientras que el resto del lienzo se completó con calicanto. En este paramento se inserta un arquillo de medio punto latericio, muy escorado hacia el tramo recto, que cobija una aspillera cegada por los revocos existentes en la cara opuesta. El ladrillo utilizado en la construcción de este vano es de similares características al empleado en el paramento del ábside y el presbiterio, especialmente en lo que a fisonomía, grosor y granulometría se refiere, y otro tanto podemos decir respecto a ciertos detalles en la técnica de ejecución, en particular la aplicación de un mortero de tendel grueso en las junturas. En definitiva, detalles todos ellos que parecen revelar una contemporaneidad de las dos estructuras puestas al descubierto, reforzando, a nuestro juicio, la hipótesis de que ambas formaron parte de una misma etapa de obra.

\section{A modo de conclusión}

Esta primera aproximación a la arquitectura de la iglesia de San Pedro de Íscar, enfocada en las evidencias supervivientes de su fase de construcción románica, arroja, en definitiva, algunas interesantes conclusiones.

En el caso de la cabecera, si bien las características arquitectónicas y ornamentales presentes reflejan su innegable similitud con respecto a la de su convecina de Santa María de los Mártires, y por ende, no ofrecen dudas en cuanto a su inclusión en el llamado foco clásico del mudéjar vallisoletano que propugnara Valdés, no podemos decir lo mismo en cuanto a la cronología, al surgir ciertas disconformidades respecto a ese discurso. Y es que, en función de los argumentos aportados y desarrollados en el presente estudio, todo parece apuntar a los años centrales de la primera mitad del siglo XIII, quizá antes, como fecha de construcción de esta estructura, extensible además a todo el edificio original, por tanto anterior en tres cuartos de siglo a la cronología tradicionalmente establecida. En suma, una datación, y un nuevo planteamiento metodológico, que abren una sugestiva hipótesis de trabajo con la que afrontar la aconsejable tarea de redefinición cronológica del mudéjar en la comarca.

Por lo que respecta al testero, y a pesar de su exigüidad, su inesperada existencia ha permitido determinar ciertos aspectos de índole estructural del edificio, como la anchura de su perímetro murario y, en consecuencia, su más que probable sistema de cubrición, sin olvidar ciertos detalles de su ejecución técnica que indudablemente le hacen coetáneo de la propia cabecera.

\section{BIBLIOGRAFÍA}

Antón y Casaseca, Francisco (1927): Catálogo Monumental de la Provincia de Valladolid. Informe en dos tomos (texto y láminas) elaborado entre 1916-1927. Depositado en la Biblioteca Tomás Navarro Tomás, Centro de Ciencias Humanas y Sociales del CSIC. Inédito.

Aratikos Arqueólogos, S.L. (2005): Intervención arqueológica en la Iglesia de San Esteban. Cuéllar (Segovia). Informe técnico depositado en la sede de la Fundación del Patrimonio Histórico de Castilla y León. Inédito.

Arranz Santos, Carlos (1995), Villa y Tierra de Íscar, Valladolid.

Brasas Egido, José Carlos (1977): Catálogo Monumental de la Provincia de Valladolid. Tomo X: Partido Judicial de Olmedo, Valladolid, Diputación Provincial de Valladolid.

Arch. esp. arte, LXXXVIII, 349, ENERO-MARZO 2015, 19-36

ISSN: 0004-0428, eISSN: 1988-8511, doi: 10.3989/aearte.2015.02 
Carrera de la Red, Miguel Ángel (1990): Las fábricas de harina en Valladolid, Valladolid, Caja de Ahorros Provincial de Valladolid.

Catalina Rico, Cruz (2013): "El derribo de una casa en Íscar descubre el ábside de San Pedro". En El Norte de Castilla, 03/01/2013, p. 13.

Gil Farrés, Octavio (1950): "Las iglesias románicas de ladrillo de la provincia de Segovia". En Revista de Archivos, Bibliotecas y Museos, T. LVI, pp. 91-127.

López Guzmán, Rafael (2000): Arquitectura mudéjar, Madrid, Cátedra.

Mañueco Villalobos, Manuel y Zurita Nieto, José (1917): Documentos de la Iglesia Colegial de Santa María la Mayor de Valladolid. Siglos XI y XII, Valladolid, Imprenta Castellana.

Martín González, Juan José (1982): Historia del arte. 1, Arte antiguo y medieval, Madrid, Ed. Gredos.

Moreno Blanco, Raimundo (2007a): "Ermita del Santo Cristo de San Mamés". En García Guinea, Miguel Ángel y Pérez González, José María (dir.): Enciclopedia del Románico en Castilla y León. Segovia, Aguilar de Campoo (Palencia), Fundación Santa María la Real, pp. 420-422.

Moreno Blanco, Raimundo (2007b): "Iglesia de El Salvador”. En García Guinea, Miguel Ángel y Pérez González, José María (Dir.): Enciclopedia del Románico en Castilla y León. Segovia, Aguilar de Campoo (Palencia), Fundación Santa María la Real, pp. 571-575.

Moreno Blanco, Raimundo (2007c): "Iglesia de San Andrés". En García Guinea, Miguel Ángel y Pérez González, José María (dir.), Enciclopedia del Románico en Castilla y León. Segovia, Aguilar de Campoo (Palencia), Fundación Santa María la Real, pp. 575-586.

Moreno Blanco, Raimundo (2007d): "Iglesia de San Esteban". En García Guinea, Miguel Ángel y Pérez González, José María (Dir.): Enciclopedia del Románico en Castilla y León. Segovia, Aguilar de Campoo (Palencia), Fundación Santa María la Real, pp. 587-593.

Moreno Blanco, Raimundo (2007e): "Iglesia de San Martín”. En García Guinea, Miguel Ángel y Pérez González, José María (Dir.): Enciclopedia del Románico en Castilla y León. Segovia, Aguilar de Campoo (Palencia), Fundación Santa María la Real, pp. 594-600.

Nuño González, Jaime (2002): "Iglesia de Santa María”. En García Guinea, Miguel Ángel y Pérez González, José María (Dir.): Enciclopedia del Románico en Castilla y León. Valladolid, Aguilar de Campoo (Palencia), Fundación Santa María la Real, pp. 224-225.

Palomino Lázaro, Ángel Luis et al. (2011): "La iglesia de San Esteban de Cuéllar. Aproximación a sus contextos histórico y arqueológico". En V.V.A.A., La iglesia de San Esteban de Cuéllar, Segovia. Cuadernos de Restauración, $n^{o}$ 10, Valladolid, Fundación del Patrimonio Histórico de Castilla y León, pp. 15-37.

Pérez Higuera, María Teresa (1993): Arquitectura mudéjar en Castilla y León, Valladolid, Junta de Castilla y León, Consejería de Cultura y Turismo.

Ruiz Hernando, José Antonio (1988): La arquitectura de ladrillo en la provincia de Segovia, siglos XII y XIII, Segovia, Diputación Provincial de Segovia.

Sánchez Merlo, Pedro (1987): "Reaparece el mudéjar y San Pedro vuelve al recuerdo", El Norte de Castilla, 22/10/1987, p. 2.

Santamaría López, Juan Manuel (1973): "El Románico de ladrillo en la villa de Cuéllar". En Estudios Segovianos, T. XXV, 74-75, pp. 445-462.

Valdés Fernández, Manuel (1981): Arquitectura mudéjar en León y Castilla, León, Universidad de León.

Valdés Fernández, Manuel (1996): “Arte de los siglos XII al XV y cultura mudéjar”. En Valdés Hernández, Manuel, Pérez Higuera, María Teresa y Lavado Paradinas, Pedro José, Historia del arte en Castilla y León. T. IV, Arte Mudéjar, Valladolid, Ámbito, pp. 9-128.

Valdés Fernández, Manuel (2007): “Arquitectura religiosa en la provincia de Valladolid: la albañilería y la arquitectura mudéjar”. En Regueras Grande, Fernando y Sánchez del Barrio, Antonio (coords.), Arte mudéjar en la provincia de Valladolid, Valladolid, Diputación de Valladolid, pp. 83-102.

Villar García, Luis Miguel (1990): Documentación medieval de la catedral de Segovia (1115-1300), Salamanca, Universidad de Salamanca.

Yarza Luaces, Joaquín (2004): Arte y arquitectura en España: 500-1250, Madrid, Cátedra.

Fecha de recepción: 20-XI-2013

Fecha de aceptación: 27-III-2014

Arch. esp. arte, LXXXVIII, 349, ENERO-MARZO 2015, 19-36 ISSN: 0004-0428, eISSN: 1988-8511, doi: 10.3989/aearte.2015.02 